\title{
Improving Health Care Facilities through Identify Challenges of Medical Social Work in Hospital Settings: The Context of Hospital Social Service in Bangladesh.
}

\author{
Md. Dipul Hossain \\ Assistant professor, Dept. of Sociology \& Social Work, The People's University of Bangladesh, 3/2, Asad \\ Avenue, Mohammadpur, Dhaka, Bangladesh
}

\begin{abstract}
Medical social work is required to navigate the increasing complex health care system and frequently make decisions that directly affect patient outcomes and to prepare for the high level of responsibility for the client. Bangladesh is highly overpopulated country, it has many problem affected directly. Poverty is one of the mostvital and significant problems. Health issue is another reflecting problem of our country, because near about 25-30 percent people are now living below poverty line. They are not to reach basic need/right. As well as medical facilities are not available in our country. They are not to reach our existing medical facilities, specially hospital settings, It has some lack of our country, illiteracy, lack of awareness, lack of government budget, lack knowledge about illness or disease etc. Social work is enabling and enhancing profession, which is support for poor patients in hospital setting. Also medical/hospital social work initiate to cope up the patients problem. Medical/hospital social work and practice are not undated. It has some major problem, which are not to perform properly. In addition to professional training, it is important for medical social workers to have strong interpersonal and organizational skills and to possess a sense of compassion. These studies identify the challenges and impact of current hospital social service in hospital setting.
\end{abstract}

Key Words: Medical, Social Work, Health, Challenges and Hospital

\section{INTRODUCTION}

The majority of medical social workers work in general medical and surgical hospitals. They are also employed by outpatient clinics; residential care facilities and home health care services. In hospital settings, medical social workers may be responsible for reviewing new admissions, handling patient discharges and following up on aftercare plans. In this capacity, they may be called upon at any hour of the day or night. Other types of support provided by medical social workers include helping patients make informed decisions about treatment options and providing advice about advanced directives and end-of-life planning(Midgley, J. 1978).In the rapidly changing societies of the so-called Global South, it is vital that certain traditional values and norms are preserved in order to prevent total social and cultural breakdown and related chaotic situation of normlessness, lack of self-identification and the absence of a sense of belonging. It is also important that these societies avoid the pitfalls of developmental mistakes experienced by developed societies. By virtue of their professional training, social workers are strategically positioned to provide the necessary safeguards in this regard.Using their professional skills and knowledge, social case workers help in assessing the clients' needs and applying agency, community and public welfare resources and programmes to address relevant social, health or economic problems. They help clients who become eligible for a variety services designed to improve their economic, social and/or health functioning, thereby working toward improving the clients' quality of life or standard of living (http://www.social workers.org).Traditionally, this approach has focused on those individuals who could not achieve a fairly normal adjustment to life and needed outside attention. It is concerned with people who are in particular situations of need. Casework is done on a person-by-person basis, in situations where privacy is necessary in attending to individual problems, for example, in a hospice, a women's shelter, or a drug rehabilitation center.The idea of a social worker acting as a caseworker or a counselor is a recurrent and powerful notion in social work throughout its history, and has also been closely associated with some of the key values of social work and particularly recognizing the inherent worth of the individual and respecting him or her. Casework also appeals to those whose view of social work as a whole is one in which helping or supporting individuals is a key component (http://www.scontland.gov.uk/). The method involves bringing change in the behavior or outlook of a client. According to (Popple and Leighninger2004: 8), social work is a core technology in social welfare institution, the institution in society that deals with problem of dependency; that is every member of society has a number of social positions or statuses that go with specified roles, and if a member fails 
to perform his/her roles adequately or social institutions fail to extend help to them, then social stability is threatened and social work has to intervene.

\section{LITERATURE REVIEW}

It is important to clarify a few basic concepts, such as social work practice, local communities, community power structure, and political engagement, for the purpose of this article. Social work practice includes all those micro- to macro-level activities (Hugman, 2009) that emanate from the internationally accepted social work definition that reads as follows: The social work profession promotes social change, problem solving in human relationships and the empowerment and liberation of people to enhance wellbeing(Friedlander, W. A. 1958).Utilizing theories of human behavior and social systems, social work intervenes at the points where people interact with their environments. Principles of human rights and social justice are fundamental to social work. (International Association of Schools of Social Work [IASSW] \& International Federation of Social Workers [IFSW], 2004)

Within the social work profession generally, its value orientation appears to be somewhat mixed (Stroup, H.H.1980)). As part of their ethical stand, social workers need, and are expected, to be non-political and non-religious in their practice (Popple, P. R. and Leighninger, L.2004). They are not expected to align or be partisans with any particular political or religious groups, but are expected to remain neutral and nonjudgmental, irrespective of their personal values and beliefs. Smyth and Campbell (1996) state that the social work code (in the U.K. context) espouses complex principles such as "respect for persons," "individuation," and "confidentiality" (p. 78), without fully acknowledging their close association with wider personal, professional, and political ideologies. This has often encouraged educators and practitioners to assume that such principles are self-evident, and politically and socially neutral. They further argue that such principles may make professionals feel comfortable, but their practice can impinge the rights of clients cited from (WHO (1998), Are such values and assumptions serving to silence discussion and action on important issues and approaches to resolving human problems? Although Smyth and Campbell, and Whiting's analysis should not be taken as a guiding edict of the profession, (Midgley, J. 1978) contend that there has been little discussion of the moral and political character of social work, and that the social work profession in many Western countries has been struggling with the withering of political bases. For example, point out a lack of political action among social workers by noting the paucity of professional publications on political issues of the times in the 1950s to 1960s (also see Although it has been argued in the developed country context, the trend is concerning because social work education and practice in developing countries is generally based on such values and principles, and practices that do influence practice within the local communities of developing country. Overall, this literature review suggests that generally, social workers and the social work profession in developing countries have neglected community practice with political engagement in local communities (Hall N.1990).

(Popple and Leighninger 2004) further point out that the social work profession has two targets, the first target is that of helping individuals who are having difficulty meeting individual role expectations, which is referred to as micro practice or clinical social work (social casework) and the other target of social work concerns those aspects of social institutions that fail to support individuals in their efforts to fulfill role expectations; this is referred to as macro practice. Social casework involves working with the client to: 1 . Assess and identify individual and family strengths and needs; 2 . Develop a case plan to provide appropriate supports and services; 3 . Implement the case plan using community resources; 4 . Coordinate and monitor the provision of services, and 5. Evaluate client progress and the case plan to determine continued need for services.Social Work in Bangladesh is now recognized at two levels. Although the two are inter-linked, one is based on the more academic level and the other on the 'community development' level. The former can be understood in the prequalifying sense (i.e. professional training), and the latter in the post-qualifying and NGO level sense (i.e. fieldwork or non-professional)(Watts T (1995). Apart from this, there is also another form of social work, which is informal. This is provided by the community or family network and stems from the traditional notion of interdependence among family members. Within this system, there is the built-in mechanism of providing services, shelter and security to the needy. Let us now move onto looking at social work in the academic sphere(Hamid \& Stalker, 1997).

\section{OBJECTIVES OF THE STUDY}

General objectives of the study are to know the challenges and prospectof medical social work in hospital settings in Bangladesh.

Specific Objectives are;

1. to know the challenges of medical social work in hospital settings.

2. to find out the prospects of medical social work practice in hospital. 


\section{METHODOLOGY OF THE STUDY}

I have been completed to the study following the qualitative methods. This study used secondary sources of information that have been collected from various types of books, e-books, journals, articles, newspapers, magazines, and websites related to patterns of medical social work practice in Bangladesh. As well as I tried to present the real fact of medical social work and providing health care facilities for the client.

\section{CONCEPTUAL CLARIFICATION}

Medical or Hospital Social Work is defined as "Social work practiced in a responsible relationship to medicine and public health within the structure of programs of health care. Initially, this field of social work practice was concerned almost exclusively with the social needs of problems of ill person s under care in hospitals and civics. Robert L. Barker defined Medical Social Work as "The social work practice that occurs in the hospitals and other health care settings to good health, prevent illness, and aid physically ill patients and their families to resolve the social and psychological problems related to illness. He also stated that medical social work also sensitizes other health care provides about the social psychological aspect of illness (Barker, 1995). They serve as case managers, counselors and advocates, providing patients and families with the nonmedical support needed to deal with acute, chronic and terminal conditions. Medical social workers also provide referrals to health care resources and help locate financial and legal assistance in the community.

\section{FINDINGS}

Social work in some areas of Bangladesh is gradually becoming recognized as a concept or an organized programme, it is still felt by the masses as an act of 'good will' or charity inspired either by a sense of religious duty or simple piety. A good hearted person with wealth and desire to serve the distressed, the destitute and the abandoned is generally regarded as social work, no professional qualification or experience is a requirement. He or she may practice charity, do reform work and be useful to any person or an institution designed to render social services. However, due to the recent policy developments both nationally and internationally, together with the ground breaking work carried out by some NGO's, there is now pressure on the government to look at ways in effectively organizing and delivering human services to the grassroots i.e. the poor, (Taher M \&Rahman A 1993). I have been found the challenges and improving factors of medical social work practice in hospital settings. Findings are;

\section{CHALLENGES}

As medical social workers often have large caseloads and have to meet tight deadlines for arranging necessary services, medical social work is a demanding job that is vulnerable to detrimental impact. Often this job requires tolerance due to its lackluster reality of unsupportive and hostile environment and crossdepartmental nature with Nursing and Public Relations, which diminishes the visibility (authority gradient) of the profession within an institution.The inadequate salary and restrained professional growth is also a major concern for Medical Social Workers. Medical social workers often deal with complex cases involving patients who come into the hospital with multiple psychosocial issues, all of which require assessment and treatment. It is not uncommon for medical social workers to tackle cases involving homelessness, chronic unemployment, lack of income, lack of health insurance coverage, history of incarceration, and substance abuse problems. Any of these problems, separately and together, can impede timely care services. Sometimes situations as seemingly ordinary as the patient needing bus fare or a decent pair of shoes can lead to delays in discharge, which could incur social and healthcare costs especially if these needs are not identified quickly and early. A poor or nonexistent relationship between assessment and interventions due to lack of structured communication (SBAR:Situation, Background, Assessment and Recommendation), policies, economic restraints could also cause this. This is why a complete and timely assessment of the patient's psychosocial needs are critical for empowering and recovery, by a medical social worker with a inventory of management, assessment and treatment skills who is practiced in functioning within the hospital's continuum atmosphere of change and shifting priorities is required. Our traditional medical services are not up to mark. It has some obstacles and challenges, which are very affecting in medical services. Social service department is not taking any initiative for health services improvement. Author tries to identify some challenges, identified challenges are:

- Social work is not recognized in our country as profession.

- Recruiting policy of Ministry of social welfare is not on right track.

- Social service officer were not background of social work/welfare discipline.

- Limited budget/fund is the major problem of hospital social service program of Bangladesh. 
- Due to limited fund the hospital social service officers can help all the poor patients. They can only help extremely poor but cannot bear the full cost of treatment. They only provide the patient with some medicines or other necessary things.

- Medical/hospital social service officers claimed that there exists lack of manpower. So that they cannot visit the patient regularly.

- Others professionals doctor, nurses and therapists even hospital authority does not want to cooperate with hospital social service officer.

- Hospital social service officer do not identify the patient directly for providing service.

- Medical/Hospital social service officers are not involved in psychosocial study, diagnosis, treatment plan, and discharge planning of the patient because they have no knowledge among these areas.

- Professionals Medical/Hospital social service department of Bangladesh is not specialized knowledge or educational background on social work/social welfare. So that they lack in professionalism in performing their duties.

\section{IMPROVING MEDICAL SOCIAL WORK PRACTICE IN HOSPITAL SETTINGS}

Medical Social Workers help the patient's and their families to manage life crises due to acute or chronic medical conditions, and focus on improving their mental and physical well-being which is done by counseling, needs assessment and psychosocial assessments, which involves a thinking process that seeks out the meaning of case situations, puts the particulars of the case in some order and leads to appropriate interventions. Hospital services/Health care management as an executive to care-coordinator or administrator is a critical role for a medical social worker, administrative responsibilities entail to ensure efficient and effective unit operation; contributing to staff development by promoting and ensuring a supportive/collaborative learning environment based on the principles of adult learning and practice standards for nurses, students and ancillary staff; performing human resources responsibilities in collaboration with the other line managers; attending administration level meetings for program launch and evaluation, budgetary decisions, augmenting CSR activities ...etc.; liaising with members of the multidisciplinary team to ensure high standards of quality and optimal management of patient care outcomes (including data collection/reporting); staff stress management due to the competing needs in patient care and ongoing continuous improvement practices to strengthen clinic processes. Psychosocial interventions with Non-clinical hospital operations, Administrative Support, Case Coordination, Health Information Management, Employee Health, Safety and Security, Supply Chain Management, Human Resources, etc. After completion the study I have found some factor, which areimproving of a Medical social work practice for the betterment of poor patients. Key factors are;

- Social work will be recognized by nationally and internationally.

- Social work/social welfare discipline graduate should be given priority during appointing social service officers in hospital setting.

- Psychosocial assessing strength and resilience of the patient, family, and social support systems to help the individual function within the community.

- Family education on the physical and psychosocial needs of its members and ways they can access internal and external resources.

- Collecting information about patients.

- Psychosocial assessment of patients.

- Budget will be revised based on need assessment.

- Following and using social work knowledge, methods, attitudes, values, principle's, strategy, skill and systems.

- Counseling for individuals, couples and families - for situations in which patients suffer from poor mental health states (e.g. depression, anxiety), and coping and adjustment difficulties. (e.g. due to loss of limb through amputation, loss of hearing, caring for family members suffering from dementia or grief and bereavement issues)

- Assessing risk of self-harm (e.g. suicide) and to others (e.g. family violence, elder abuse, child abuse).

- Other professionals doctor, nurses and therapists even hospital authority will cooperate with hospital social service officer.

- Social service officer identify the patient need and directly providing service.

- Social service officers will be involved in psychosocial study, diagnosis, treatment plan, and discharge planning of the patient because patients didn't know among these areas.

- Financial assessment and fund management, identifying and referring cases for financial assistance. 
- Continuation, Coordination \& Discharge Planning - ensure efficient unit operation by working professionally together with medical, nursing and other allied health staff, patients and their families to produce high quality work and to develop, implement the post discharge care plan.

- Linking with another more institutions for patient referral services.

\section{CONCLUDING REMARKS}

In this article, the author has defined the challenges of medical social services in hospital settings in Bangladesh. Also author found some factors for improving medical social work system for the betterment of poor patient. Within the context of these services an attempt was made to establish the relationship between the two concepts challenges and improving of medical social work. The contributions of medical social work makes to development health condition of our country. Medical social work has been discussed through the presentation of the various approaches or strategies employed by social workers throughout the world and the role of medical social work in its totality in hospital setting and present realities for development of poor people. The most important contribution of medical social work perhaps is the consideration it gives to the health, human, mental, economical, cultural, environment and social sides of development. This is essential in orderimproving health condition with identify challenges of medical social work in hospital settings.

\section{REFERENCES}

[1] Barker Robert L (ed 1995) Social Work Dictionary, NASW, New York.

[2] Bernstein, A. J. (1995) Redefining social work's emphasis on the 'social': the path to development., In: International Social Work. 38, 53-67.

[3] Friedlander, W. A. (1958) Concepts and methods of social work. Englewood Cliffs, N.J, Prentice-Hall.

[4] Hall N.(1990). Social work training in Africa: A fieldwork manual [Supplemental material]. Journal of Social Work Development in Africa.

[5] Hamid S \& Stalker P (1997), Bangladesh and United Nations Partnership in Progress, Dhaka Press, Bangladesh.

[6] International Association of Schools of Social Work [IASSW] \& International Federation of Social Workers [IFSW], 2004.

[7] Midgley, J. (1978) Developmental roles for social work in the Third World: The prospect of social planning, in: Journal of Social Policy. 7(2), 173-188.

[8] Popple, P. R. and Leighninger, L. (2004) Social Work, Social Welfare, and American Society. Allyn\& Bacon.

[9] Stroup, H.H. (1980) Social Work. An introduction to the field. New York, American Book Co.

[10] Taher M \&Rahman A (1993), Social Work in Bangladesh: Problems and Prospects, The Indian Journal of Social Work, Vol.4, Oct 1993.

[11] WHO (1998), The World Health Report 1998: A Vision for All, WHO, Geneva, Switzerland.

[12] Watts T (1995), International handbook of Social Work Education, Greenwood Press, London. 